\title{
Application of Iconicity to English Teaching
}

\author{
Tinghua $\mathrm{Li}^{1}$ \\ ${ }^{1}$ Faculty of English Language and Culture, Guangdong University of Foreign Studies, Guangzhou, China \\ Correspondence: Tinghua Li, Guangdong University of Foreign Studies, No. 2 Baiyun Avenue, Guangzhou City, \\ China. E-mail: ting82631@163.com
}

Received: January 31, 2020

Accepted: March 2, $2020 \quad$ Online Published: March 8, 2020

doi:10.5539/hes.v10n2p13

URL: https://doi.org/10.5539/hes.v10n2p13

\begin{abstract}
The theory of iconicity is widely applied in different fields such as poetry, novel, advertising and English-Chinese comparison but scarcely is it utilized to the combination of English teaching and iconicity theory in cognitive linguistics. This paper discusses how iconicity theory can be used in English teaching by literature research method. Once teachers become familiar with iconicity theory and apply it to their teaching activity, English teaching and learning would be encouraged for they are a rewarding journey, promised with a host of knowledge.
\end{abstract}

Keywords: iconicity, grammar teaching, vocabulary teaching, translation teaching, phonetic teaching

\section{Introduction}

English is playing an essential part in improving students' academic performance, giving them an edge on standardized test and developing a positive attitude to various cultures and acquisition of language skills. However, it is rather difficult for students to recite a large number of vocabularies and boring grammar rules, to understand the content of a text and to translate it without any efficient method. In fact, it bothers both students and teachers. Teachers used to complain students' laziness on word learning. Overemphasizing time and efforts in learning and teaching instead of the efficiency of learning and teaching is no doubt putting the cart before the horse because the usual way to learn English is a time-consuming task. Therefore, researchers get down to cognitive field of English teaching and acquisition under the influence of cognitive science and cognitive linguistics (Givón, 1995). Researches become meaningful and valuable on English teaching under the guidance of the iconicity theory in cognitive linguistics.

The definition of iconicity was first put forward by C. S. Peirce. He argued that is a relation between a sign and its object in which the form of the sign represents the object. This definition reveals that different types of events and entities can be contained into its scope ( $\mathrm{Du}, 1996)$. Iconicity becomes a topic in many fields such as semantics, cognitive psychology, transportation, etc. However, iconicity, one of functional principles of language organization, demonstrates the resemblance between the signifier and the signified, onomatopoeia and interjection, for examples. But few of them exist. Extremely broad definition of Peirce destroying its accuracy, scholars embark on defining iconicity in a light of linguistic structure and concept. For example, Shen (1993) argued that there is an intrinsic relationship between syntactic structure and conceptual structure. This understanding is mostly restricted to the syntactic level, ignoring levels of phonology, morphology, word formation and language change. Some scholars embark on defining iconicity by virtue of "signifier" and "signified". For example, Wang (2005) saw iconicity as a naturally corresponding characteristic between the signifier and the signified, but he failed to make clear what is the signifier and what is the signified. Others are prone to define iconicity by means of "form" and "meaning". For instance, Haiman (1980) defined iconicity as "there is the relation of resemblance between a set of signs and their forms". Fromkin (2005) regarded iconicity as "a non-arbitrary relation between form and meaning in which the form possesses the resemblance to its meaning". Loose as they are, these definitions represent a range of forms, meanings and potential similarity between them, which reveals that types of iconicity might be confirmed from basic onomatopoeia to a complex relationship between syntactic and mental concepts. The meaning of "form" and "meaning", however, is fairly vague in linguistic study. Form presents linguistic units, such as the distinctive sounds of phonemes, words, phrases and sentences. Meaning describes not only a linguistic concept but also a crucial issue in be it philosophy, psychology or semiotics. Additionally, the use of other terms---"content", "reference", "sense" and "designation" has resulted in numerous overlapping. That is, if a linguistic sign is regarded as the combination of form and 
meaning, then it would be quiet incompatible with another.

Nowadays, this definition is widely accepted: Iconicity refers to the natural resemblance between the form of a sign and the concept that can describe the nature world or perception of people (Fan, 2013). Thus iconicity can be viewed as a crucial quality of language on the condition that iconicity is extended to include many types of similarity.

\section{Application of Iconicity to Grammar Teaching}

\subsection{Principle of Distance Iconicity}

Haiman (1980) referred to the iconicity of distance as "the linguistic distance between expressions corresponding to the conceptual distance between them". This principle is widely used to English grammar teaching in terms of dynamic distance, the distinction between non-restrictive attributive clause and restrictive attributive clause, the order of adjectives and the order of adverbials.

\subsubsection{Dynamic Distance}

There are two kinds of verb-object collocation: one is the verb followed directly by the object; the other is the verb indirectly followed by the object with preposition in between. For example, when it comes to phrases "know sb." and "know of sb.", the previous phrase expresses a direct relationship (directly know someone) and the latter an indirect relationship (indirectly know someone). If English teachers are able to analyze these phrases from the perspective of iconicity, the effectiveness and efficiency of teaching may be greatly improved (Hao, 2006). There is another example: "he gives me a book." and "he gives a book to me." The previous sentence values "he gives me not anyone else a book"; the latter one mainly emphasizes "he gives a book not anything else to me". The theory of distance iconicity would become a useful intermediary which can surely arouse people's passion for language learning by affording them the ease in receiving information.

\subsubsection{Non-restrictive Attributive Clause and Restrictive Attributive Clause}

Non-restrictive attributive clause and restrictive attributive clause are easily mixed up by students in learning and application. In fact, the principle of distance iconicity can allow students to master the essential differences between them and employ them flexibly (Hao, 2006). As far as form is concerned, there is a comma between the antecedent and its non-restrictive attributive clause. Hence, the relatively long distance between them leads to the long conceptual distance between them. The clause, just a further explanation of the antecedent, would not affect the completeness of the meaning of the whole sentence. While the absence of a comma between the antecedent and the head word of the restrictive attributive clause shows the closeness of the conceptual distance between them. Without the clause, the meaning of the sentence would be incomplete. Examples are as follows: (a) The man who came here yesterday has come again. (b) My cousin failed the examination, which made her pretty sad. If the clause "who came here yesterday" in sentence (a) is removed, it goes against the goal to express clear and complete meaning, while sentence (b) is still a complete sentence after removing the clause "which made her pretty sad". Students are bound to be taught from the perspective of iconicity so that they can connect linguistic forms with linguistic meanings to have an overall grasp of these two types of clauses, to distinguish and to apply them.

\subsubsection{Order of Adjectives}

The order of multiple adjectives before the head word can be better grasped with the help of the principle of distance iconicity (Hao, 2006). In English, when multiple adjectives jointly modify a noun, the closer an adjective is to the concept of the head word, the closer it is to the head word. Objective characteristic is the essential attribute of a thing or a concept, so it should be closer to the modified head word than subjective characteristic. In this way, the general order of several adjectives is subjective adjectives preceding objective adjectives, for example: Jack gave Anne a beautiful cotton skirt as a present. When several objective adjectives modify it at the same time, the source, material and use of the head word are more essential than the size, shape and color of it. Therefore, the order of multiple adjectives should be: determiner + subjective adjective + size + shape + color + source + material + use + the head word (Zhang, 2013). That is a kind of principle of distance iconicity, that is, the distance between adjectives and the head word corresponds to the distance between the concepts of them. Taking "What a charming small round brown French oak writing desk!" as an example. Writing is the most essential nature of the desk, so it is the closest to the head word. "Oak" describes the "material", "French" the "source". Brown is an obvious external feature, which can be seen from outside, so it is more essential than shape "round" and therefore following "round". From "brown" to "round" to "small" to "charming", it is shown that the subjectivity is increasing. It, therefore, can be said that the order of these adjectives lies in the distance between the concepts of adjectives and that of the head word "desk". 


\subsubsection{Order of Adverbials}

The order of adverbials of different nature can be seen from the following sentences: (a) The boy waited patiently at the airport that day. (b) The boy waited at the airport that day patiently. (c) The boy waited patiently that day at the airport. Which sentence sounds more natural? It is easy to see that (a) is the most natural one. Why do the manner adverbial "patiently" precede the place adverbial "at the airport" and the place adverbial precede the temporal adverbial "that day"? Again, the principle of distance iconicity can explain this (Hao, 2006) The core of these three sentences is to describe the action "waited". The order of these three adverbials mainly relies on the distance between the concepts of them and that of "waited". The adverb "patiently" is a way of explaining "waited". It is the closest to the concept of "waited", so the syntactical relationship of them should also be the closest. "At the airport" belongs to place adverbial, which is intuitive and visible, so it is closer to the concept of "waited". "That day", a time adverbial, is an abstract concept, so it is not close to the notion of "waited", and therefore is placed at the end of the sentence. With the support of the theory of distance iconicity, students can better understand the order of adverbials without suffering cramming.

\subsection{Principle of Quantity Iconicity}

The principle of quantity iconicity refers to the fact that the information language units express depends on the quantity of them (Liu, 1997). In other words, the more the language units, the more the content. Here, the principle of quantity iconicity is discussed with respect to the emphatic sentence, repetition, passive sentence and exclamatory sentence.

\subsubsection{Emphatic Sentence}

Many English beginners appear to have no idea with English emphatic sentence. But, students would be suddenly enlightened if they are taught with the principle of quantity iconicity (Dong, 2010). Different from a declarative sentence, an emphatic sentence can inflect more meanings that the listener should attach much importance to. Therefore, the amount of information of it is naturally more than that of a declarative sentence. Here is an example. (a) The children broke the window. (b) It is the children who broke the window. Obviously, (b) is more complex than (a). (b) implies that it is not anyone else but "the children" who broke the window. However, (a) just states a fact objectively.

\subsubsection{Repetition}

According to the theory of quantity iconicity, more information can be expressed with more language signs. There is an advertisement---This baby's nappy is Lux-safe. Safe with the safety that you get with pure soup (Lux perfume ad). The concept "safety" is expressed again and again to highlight the fact that it is safe and reliable to use Lux products. People are very concerned about the safety of a product and its impact on physical health. And this advertisement uses the rhetorical device of repetition to satisfy the psychological needs of consumers thus obtaining better advertising revenue, which also testifies that the principle of quantity iconicity is beneficial to teachers and students in English teaching and learning in terms of the compound word, the singular and plural forms of a noun and the comparison of an adjective and an adverb in the comparison level and the highest level (Zhang, 2001).

\subsubsection{Passive Sentence}

Passive sentence is also a fine example (Dong, 2010). In many cases, some information is known to both sides of the conversion with no need for explanation. Sentence "I can not be changed in the meeting" indicates that "in the meeting, I can not be changed by others". Another example is "It is said/reported/estimated that...". People who say/report/estimate are known to us. Therefore, action actors are not necessary to appear at all in the sentence. In essence, completely predictable information is often abbreviated or omitted in expressions.

\subsubsection{Exclamatory Sentence}

Similarly, the principle of quantity iconicity can contribute a lot to the explanation of the exclamatory sentence in English (Fan, 2013). It is more likely for speakers to express the feelings of praise, surprise and joy not with a declarative sentence but with an exclamatory sentence. In other words, more information would be expressed. Look at the following examples: (a) He is a great actor. (b) What a great actor he is! (c) How great an actor he is! In these three sentences, (a) is a declarative sentence, while (b) and (c) are exclamatory sentences. Compared with (a), (b) and (c) contain interjections---"what" and "how", so more information is expressed by linguistic signs indicating exclamatory meaning. That is, both (b) and (c) express the speaker's admiration for this "actor", which is not reflected in (a). 


\section{Application of Iconicity to Vocabulary Teaching}

\subsection{Principle of Phonological Iconicity}

This section illustrates how to apply the principle of phonology into practice in terms of onomatopoeia and phonaestheme, which are two sub-types of phonological iconicity (Hao, 2006). The understanding of onomatopoeia and phonaestheme, which is frequently faced by English learners during the process of learning, is conducive to improve students' reading comprehension and writing skills (Cai, 2012). From the author's perspective, teachers should impart the nature of the seemingly complex language phenomena and help students memorize and apply onomatopoeia and phonaestheme flexibly. In this way, students are able to form a good habit of accumulating English words. Onomatopoeia can be viewed as the fact that the pronunciation of a word is similar to the thing it describes (Dai, 2004). These words are created by imitating the sound pronounced by people: chatter, chuckle, giggle, snigger, etc. The words imitating the sounds produced by animals are: moo, miaow, roar, etc. These words imitate the clash of metals: clank, clink, ting, tinkle, clang, etc. Phonaestheme is also known as sound symbolism for the sound of a letter or a group of letters can symbolize certain concepts. Lateral consonants $/ 1 /$, nasal consonants $/ \mathrm{m} /, / \mathrm{n} /$ and fricative $/ \mathrm{r} /, / \mathrm{s} /, / \theta /$ might be used to deal with slow and noisy situation for they sound deep and vague. The sound of /gl/ could be related to shiny things, like "glimmer", "gleam" and "glitter". What's more, the sound of /s/ could be associated with that of wind, water or snake. The sound of /gr/ usually symbolizes boring and unpleasant voice, "groan", "grumble" and "grouch", for example. In addition, the sound of / h / indicates "making efforts", such as in "haste", "heavy", "hurry", etc.

\subsection{Principle of Morphological Iconicity}

\subsubsection{Derivation}

Derivation means the forming of a new word from an existing word, often by adding a prefix or a suffix (Hao, 2006). A multitude of words created by affix assure us that it serves as a useful approach. Firstly, mastering the meanings of a variety of affixes and roots could do students a favour to recite the meanings of words and to guess those of the unknown ones. For example, given our understanding of the meanings of affixes, we can, more or less, speculate about the meanings of the words including them, such as, intra- (within)---intramural, intrastate, intravenous; inter- (between)---interfere, intermediate, international, intervene; non- (not)---nonchalant, nonentity, nonessential; auto- (self)---automatic, automation, autonomy; over- (too much)---overcharge, oversensitive, overdue; proto- (first)---protocol, protoplanet, prototype; -ful (full)---handful, useful; -less (not)---fearless, endless, needless; -er (doer)---worker, teacher, learner; -en (verb)---harden, deepen, brighten. If students could divide words into prefix, root and suffix, they would know the meanings of words by connecting the meanings of those components. For example, the word "conjunction" can be analyzed into con (together) + junct (to join)+ ion (the act or result of); "manufacture" into manu (hand) + fact (to make) + ure (the act of), "systematic" into sys (together) + st (to stand) + em (used to form nouns), etc. The other way is the association among words that share the similar part like words "value", "valuable", "valueless", "valued", etc. By doing so, students are capable of enlarging their vocabulary as quickly as possible.

\subsubsection{Compound}

Compounding refers to a longer word combined by two or more words. For example, foot + ball $\rightarrow$ football $(\mathrm{N}+$ $\mathrm{N})$; brow + beat $\rightarrow$ browbeat $(\mathrm{N}+\mathrm{V})$; break + water $\rightarrow$ breakwater $(\mathrm{V}+\mathrm{N})$; through + out $\rightarrow$ throughout (Prep + Prep). Compounding is widely used in vocabulary acquisition. Just as Bolinger (1980) said, the production of compounding is limitless since words combine freely. They tend to be analyzed into several components that are semantically clear. In this way, students can figure out some words based on the meanings of every part of them. Of course, not all compounding processes are predictable. Exceptions exist in "blackbird" which does not mean any bird that is black, but mean a bird of one particular species. Again, "White House" is not any house that is white but the official home of the President of the US in Washington, DC or the US president and his or her officials. Certainly, these kinds of compounds are only in the minority. All in all, applying morphological iconicity can help students comprehend the meaning of words effectively and save a lot of time and efforts by enlarging their vocabulary rapidly (Hao, 2006).

\subsection{Principle of Semantic Iconicity}

This section discusses semantic iconicity in the light of metaphor, polyseme and origin of words (Hao, 2006). Metaphor, a metaphorical concept system, means "human conceptual system is metaphorically structured" (Lakoff \& Johnson, 1980). Metaphor is mostly employed as a device in a song or a poem. In fact, all of us in our routine life speak, write, and think in metaphor, such as, "cabbage heart", "lose heart", "heart land", "have no heart for", "sweet heart" and "the heart of a problem". Metaphor is sometimes constructed through our common 
language (Hiraga, 1994). Thus, it's commonly believed that students also can comprehend it well. Moreover, polyseme plays a crucial role in the extension of the meaning of a word. Word, in reality, is not polysemous at the beginning, but the process from monosemantic meaning to the current polysemy is not arbitrary. Nowadays, some novel meanings have started to appear against the background of our general assumptions about a word. This is a typical example---"My brother is the black sheep of the family" because "my brother" is certainly not a sheep but a person. However, we can use "the black sheep" to describe "my brother" for he is considered bad or embarrassing by other people in our family.

\subsection{Principle of Word Order Iconicity}

Word order iconicity shows the phenomenon that the order of language symbols is in line with some laws---the linear array of word order between phrases can mirror human cognition and thinking (Zhao, 2001). Word order iconicity is mainly reflected in the sequence of time and space. With respect to time sequence, expressions of this kind include "life and death" and "from dawn to night". As far as space sequence is concerned, there is a various standard---from top to bottom and from inside to outside, such as "heaven and earth" and "hand and foot". These typical examples reveal people accustom themselves to looking at the outside world on the basis of themselves. Moreover, a few of English phrases abide by the rules: from positive to negative---"right or wrong", "yes or no", "good and bad", "for better or for worse", "plus and minus", "true or false", etc; from original form to comparative and even superlative---"make better best" and "from good to better"; from near to far---"here and there" and "now and then".

\section{Application of Iconicity to Translation Teaching}

\subsection{Application of Iconicity to Sentence Translation Teaching}

English language is highly grammatical; however, Chinese language is a bit loose. As a result, Chinese is more likely to directly build a mental picture of reality than English. Meanwhile, the syntactic framework of English is subject-predicate $(\mathrm{Fu}, 2003)$, which requires words to match correctly, while that of Chinese is topic-comment, which does not command concord. All in all, English is grammatical syntax and sentence-targeted and Chinese is semantic syntax and discourse-targeted.

The basic task of translation is to find a version that is as equivalent as possible to the original text or to realize the greatest iconicity between the translated text and the original text (Nida, 1993). English syntactic framework always applies SP structure, so subordinate sentence is more common than coordinate sentence. However, in Chinese, coordinate sentence is more widely used. Just as the old saying, "Only two things are infinite, the universe and human stupidity, and I'm not sure about the former". This is a compound sentence connected by “and”. The corresponding Chinese version is full of coordinate clauses: “只有两件事情是无法估计的, 宇宙和 人的愚蚌行为, 我不肯定的是前者”. When translating Chinese into English, certain conjunctions should be added, and vice versa (Feng, 2002). In reality, in English, this kind of technique is usually employed in giving instructions. For example: Steps to create a backup system image, you have to follow certain instructions: "1. Open the Control Panel. 2. Click System and Security. 3. Click Backup and Restore. 4. Click Create a system image in the left panel. 5. You have options for where you want to save the backup image: external hard drive or DVDs. I suggest the former, even if your computer has a DVD-RW drive, so connect your external drive to your PC, select On a hard disk and click Next. 6. Click the Start backup button". Armed with the above discussion, it is fair to say that teachers should cultivate the awareness of iconicity in students' minds.

\subsection{Application of Iconicity to Text Translation Teaching}

\subsubsection{Principle of Sequence Iconicity}

There are two main sequences in the English and Chinese texts, namely, time sequence and space sequence ( $\mathrm{Li}$, 2008). According to Shen (1993), "The order of syntactic elements reflects the order in which they are expressed in a series of events". As far as translation is concerned, the translation at the textual level through sequence iconicity should be based on the sequence of the source language with few of adjustments.

Firstly, although Chinese language follows the chronological iconic principle to a greater extent than English one at the syntactic level (Wang, 2002), the chronological iconicity exists in both languages at the textual level, such as novel or historical story. In the same way, the same temporal order must be mirrored in cross-language translation. Look at the following two examples at the level of sentence group: (a) "Not a syllable passed aloud. They all waited in silence for the appearance of their visitors. His footsteps were heard along the gravel path; in a moment he was in the passage; and in another, he was before them"(Jane Austen, Sense and Sensibility). The first two sentences describe the background for the last sentence; the last sentence is the core of the description; the three clauses that make up the last sentence are arranged in the chronological order. Thus, that paragraph 
follows the principle of time sequence iconicity on two aspects: to begin with, the first two sentences and the last sentence possess temporal iconic features for the reason that there is the background before an event itself in the real world; secondly, the three clauses in the last sentence directly reflect chronological order, which is an explicit application of time sequence iconicity. In contrast, the first one can be said to be implicit application of temporal iconicity. The above two aspects of time sequence should be expressed by the corresponding tactics in the target language during translation. The following is a Chinese example: (b) “那日, 正是黄梅时候, 天气烦 躁。王冕放牛倦了, 在草地上坐着”. This is a typical Chinese narrative way---“rendering the background before depicting events", which also conforms to time sequence iconicity (Zhang, 1998). And the two clauses in the last sentence follow the natural cognitive sequence of "causal relation". Although the order of the original text is adjusted in order to comply with the expression habits of English language, the following translation is a successful reproduction as a whole: "One sultry day in early summer, tired after leading the buffalo to graze, Wang Mian sat down on the grass."

Secondly, the basic relative spatial positions in nature include upper (middle) lower, front (middle) back, left (middle) right, inner (middle) outer, far (middle) near, etc. Generally speaking, the description of spatial things is influenced by human cognition based on physical experience and mostly based on human visual perception. For example, humans' habits of expressing "up and down" and "high and low" lie in the characteristics of human walking upright and the gravitation of the earth. The expression "front and back" is created by the fact that major human sensory organs always face the front. In addition, the phrases such as "near and far", "the whole and the part" and "large and small" are derived from human visual perceptual laws: near things are more obvious than distant ones, the whole the part and large small. And the expression of "from inside to outside" or "from outside to inside" depends on the reference point of the visual perception: people inside tend to adopt the former while people outside the latter. Here are two examples. 1 (a) “莫高窟大门外, 有一条河, 过河有一溜空地, 高高低 低建着几座僧人圆寂塔”. The English version is: 1 (b) “Outside the entrance to the Mogao Grottoes flows a river, and across the river is a piece of land on which stand several stupas in honour of the deceased abbots of the Mogao Grottoes" ( $\mathrm{Li}, 2002)$. There is the near-to-distant spatial description order in the original text. Although only one spatial marker “外” is applied, the parataxis of Chinese language shows orderly description. Therefore, the English version adopts the same spatial sequence as the original text with three spatial marker words "outside", "across" and "on which", better simulating the spatial sequence of the original text. Below is the first quarter of the poem Snowflakes written by H. W. Longfellow: 2 (a) "Out of the bosom of the air/ Out of the cloud-folds of her garments shaken/Over the woodlands brown and bare/Over the harvest-fields forsaken/ Silent, and soft, and slow descends the snow". In this verse of the poem, the order H. W. Longfellow describes is: sky-clouds-trees-fields. This is the order in which snowflakes actually fall from top to down. What's more, the poet intends to put the word "snow" at the end of the verse, apparently mapping the final position of the falling snow within the visual range of people. In reality, this is not only the description of the falling snowflakes in spatial sequence, but also the reflection of them in temporal sequence. Accordingly, precisely speaking, the poet employs the spatiotemporal sequence here. The identical expression sequence should be used to achieve the same visual effect during the process of translation in target language. In this way, the corresponding beauty in sense is conveyed through the reproduction of the original form beauty. Based on this, the text can be translated into it: 2 (b) “从天宇深处, 从飘动着她的长袍的云层里, 漫过光秃秃的褐色林木, 漫过收获后废弃的田地, 悄悄, 轻轻, 缓缓, 飘下雪花一片” (Chen, 1995).

\subsubsection{Principle of Quantity Iconicity}

There is a kind of coherence between the number of linguistic forms and that of meanings. In other words, the more the forms, the more the meanings. The number of sentence, the length of a text or the times of repetition can be applied to reflect the additional meaning. As for the quantity iconicity, Chinese language and English one have much in common, so the translation between them can employ the corresponding quantitative form $(\mathrm{Li}$, 2008). For instance, in the poem The Prairies, the poet W. C. Bryant makes use of extravagant length of 123 lines to reflect the vastness and continuity of the American prairie. Here are a number of textual iconic techniques to map the description of the characteristics of that prairie. This kind of structure should be consciously remained in order to reproduce the structural information that is conveyed by the form and to shed light on the poet's creative intentions. The principle of quantity iconicity is not only used for poem creation, but also applied to creation of story and novel. Please look at the following example: (a) "I am still trying to remember how she managed to push herself in with a baby on her right arm, a traveling bag in her left hand and two children, a boy and a girl, about three and five years old, following after her" (Jesus Colon, Little Things Are Big). In this example, the main sentence is followed by a super-long independent subjective structure (as shown in the italicized part). This structure is composed of three successively lengthened parts. It seems that the 
text is too lengthy. And especially it is difficult to understand why Jesus Colon points out the specific age of the two children and even their sex. Instead of "and two little children following her", Jesus Colon intentionally chooses to provide a specific description---"and two children, a boy and a girl, about three and five years old, following after her"? According to the quantity iconicity theory, the super-long adverbial clause used in this sentence expresses additional information. When it comes to structure and information, the complexity of latter sentence is greater than that of the former one (Han, 2000). It can be seen that this is a result of the author's intention to use quantity iconicity: to deliberately lengthen this independent structure is a perfect foil for the difficulty the woman have in looking for the children and carrying luggage during the journey. The description enables readers to feel the hardships the woman experiences by a sense of fatigue during the process of reading and thus to better understand the author's intentions. Based on this understanding, rhetorical intentions of quantity iconicity should be reproduced in the course of translation in order to convey the original text. According to this, it might be translated as follows: (b) “我现在仍然依稀记得当时她如何右手抱着个婴儿, 左 手跨着个旅行包, 还带着两个孩子---一个男孩, 一个女孩, 大约三岁和五岁模样, 跟在她身后拼命挤上 车”.

What's more, sentence (a) not only exists in the first paragraph in that short story. The author Jesus Colon reuses it with few adjustments in the following two paragraphs. Obviously, the use of cross-paragraph repetition technique create a sense of "redundancy" in the minds of readers. Nevertheless, this is exactly what the author Jesus Colon intends to do: the increase in quantity caused by repetition would give a vivid picture of the unpleasant state of the heroine. With respect to translation, this type of designed quantity iconicity based on the whole work should be the key for the translator to successfully translate the entire story.

\subsubsection{Principle of Symmetry Iconicity}

Principle of symmetry iconicity reveals that some information that show symmetry in its form is also of conceptually equality and importance (Zhao, 2001). In other words, the juxtaposition of the same or similar linguistic forms implies that of the similar meaning or ideology. Symmetry iconicity is a typical rhetorical device and thus the identical method is required to convey the same rhetoric and communicative effect. The symmetry iconicity in the textual level is mainly achieved through rhetorical devices such as parallel structure and chiasmus.

In Guan Yu (Book of Songs), there are three parallel verses: “1) 参差荇菜, 左右流之。2) 参差荇菜, 左右采 之。3）参差荇菜, 左右芼之。”. According to the symmetry iconicity of "similar form and similar meaning”, these three sentences should carry similar meaning. The words “流”“采”and “芦” should be synonymous---virtually, every one of them means "take". However, Xu (1992) translates the above three sentences as ---“1) Water flows left and right/Of cress long here, short there 2) Now gather left and right/Cress long or short and tender 3) Feast friends at left and right/On cress cooked tender". Obviously, Xu's version is not in line with parallel structures of the original text. In contrast, the translation of Yang (1983) can be better express both the original form and the original content for it possesses the same parallel structure as the original text (Lin, 2001)---“1) Short and long the floating water plants/left and right you may pluck them 2) Short and long the floating water plants/Left and right you may gather them and 3) Short and long the floating water plants/Left and right you may collect them". It is shown that the importance of the parallel structures for the translation of such forms. Another typical symmetrical iconic rhetoric is chiasmus, whose basic structure is $a b b a$ (Lu, 1998). There is a clear cyclic symmetry between components. And this structure is suitable to show the dialectical relation between two things. With respect to translation, the corresponding translation should be produced from the perspective of symmetry iconicity (Jakobson, 1987), conveying the original form and the beauty of the content to the readers of the target language at the same time. For example:

$$
\begin{gathered}
\text { “你站在桥上看风景, } \\
\text { 看风景的人在楼上看你。 } \\
\text { 明月装饰了你的窗子, } \\
\text { 你装饰了别人的梦。” }
\end{gathered}
$$

The poet employs this cyclical form to express the feeling of union between human beings and the world: in the first stanza, the poet connects “你 (you)” and “风景 (scenery)” together and in the last stanza, “你 (you)" and “装饰 (adorn)” are linked, which is like a wonderful particular situation in the real life. In translation, this kind of feeling should be expressed in that it is a very crucial part in this poem. The following is the English version:

$$
\text { "When you watch the scenery from the bridge, }
$$

The sightseer watches you from the balcony. 
The bright moon adorns your window,

While you adorn another's dream."

\section{Application of Iconicity to Phonetic Teaching}

There have been some thorny issues in phonetic teaching in colleges. To begin with, universities, to some degree, do not attach enough importance to English phonetic class. It is said that quite a few of universities reduce classroom hour of phonetic teaching and even do not have English phonetic class. As a result, college students lack a systematic study of English speech sounds with undesirable speech tones and dialectical English pronunciation, which would exert a bad influence on their spoken language communication. Secondly, the traditional teaching methods applied by teachers in the process of phonetic teaching are extremely monotonous---generally speaking, reading after teachers or listening to the tape and then letting students imitate to read. Hence, it is difficult to improve students' initiative in learning English speech sounds.

English pronunciation is an indispensable condition for bettering English listening and speaking of students. Therefore, it is of great significance for college students to systematically grasp phonetics. Based on the current situation of college English phonetic teaching, the author holds the view that it is necessary to connect phonetic iconicity theory with English phonetic teaching to improve the teaching quality.

The phonetic iconicity is an essential part of the study of iconicity theory in cognitive linguistics. Phonetic iconicity refers to a certain characteristic that an independent sound reflects the objective world. The phonetic iconicity can be regarded as the correspondence between the sound and the meaning it represents. Landsberg (2011) considers that the phonetic iconicity should be divided into two categories: auditory iconicity---one sound directly mimics another sound; sound iconicity---sound is connected with concept or sense. His theoretical studies provide a crucial perspective for English phonetic teaching.

According to the classification of phonetic iconicity, college English phonetic teaching can adopt the following strategies. In terms of auditory iconicity, teachers should focus on the role of phonetic imitation in the classroom. Instead of boring traditional teaching methods, teachers are bound to employ rewarding means to stimulate students' initiative. The features of English rhythm mainly include tone, stress, intonation, pitch, length, as well as speech sounds. Moreover, stress represents the mark and soul of English, which allow students to perceive English pronunciation well. But due to the bad influence of mother tongue, speech sounds are the most difficult for college students to grasp. Fortunately, with their repeated occurrence, the contrast between strong beats and weak beats in music melody has much in common with the rhythm of English speech sounds. Therefore, music can be integrated into English phonetic teaching. In classroom teaching, teachers can make use of the iconicity of rhythm of music beats and that of English to allow students to imitate the right pronunciation and intonation, which would benefit students and teachers a lot.

As for sound iconicity, teachers can choose to introduce the English film dubbing in the classroom since English movies can offer students good demonstration effect---they not only convey the characters' conversational information, but also intuitively tell students the correct mouth shape and corresponding body language on certain occasions. For instance, it is necessary to produce clear and full vowel sounds. In addition, when producing consonants, students should pay much attention to the place of articulation. For example, the labiodental $/ \mathrm{v} /$ is produced when the lower lip is brought into contact with the upper teeth. However, the dental sound, $/ \theta /$ is created between the tip of the tongue and the upper teeth. In the production of $/ 1 /$, the tip of the tongue is brought into contact with the upper teeth-ridge to create the obstruction. The velar $/ \mathrm{k} /$ is produced when the back of the tongue is brought into contact with the velum, or the soft palate. To learn phonetics is to experience sounds, to control the tongue and to do oral gymnastics, which are challenges for students. Consequently, in order to achieve an ideal dubbing effect, students should try their best to repeatedly observe and mimic the native speech sounds, speech patterns, and body language. Through continuous practice, they are expected to quickly acquire the correct pronunciation skills and to lay a foundation for fluent spoken English. And given that they spend much time in dubbing English movies, students' own interest in learning English would be aroused and the teaching effectiveness of their teachers would be improved.

Mastering English pronunciation is a prerequisite for college students' listening and speaking, which is of great significance for their future study and professional development. Absolutely, English pronunciation should be paid much attention to by colleges, teachers and students. Accordingly, the author combines the phonetic iconicity theory with English phonetic teaching to explore effective teaching methods to provide new strategies and ideas for phonetic teaching. 


\section{Conclusion}

\subsection{Major Findings}

For past few decades, iconicity has been a key term in cognitive linguistics attracting many scholar's attention. It has been studied by a number of linguists from different perspectives. Remarkable achievements have been achieved.

Although the author is approval of the theory of iconicity all the time, it does not mean that the view of arbitrariness is completely objected. In reality, "there is no contradiction between iconicity and arbitrariness since they are complementary to each other" (Saussure, 1991). Due to the correspondence between linguistic signs and meanings, the theory of iconicity is instructive to English teaching. If students are guided to recognize the correspondence between English forms and meanings, they would master the differences between English thinking and Chinese one because their interest in learning English is aroused and their linguistic sense is strengthened. In short, the principle of iconicity is conducive not only to students' understanding of English knowledge but also to English teaching. As a result, the research on iconicity has both theoretical and practical value. And the theory of iconicity is applicable to the study of foreign language teaching, which certainly can exert a positive influence on language teaching.

Theoretically speaking, iconicity is highly functional, for the study of iconicity would be a means to further understand the nature of language and the relation between a sign and a concept (Hu, 1996). Iconicity would facilitate language analysis and thus make language teaching and learning more effective. The analysis of iconicity and its application from the perspectives of grammar, vocabulary, translation and phonetics have presented a clear picture of this theory. Theory aims to serve the practice. Therefore, this paper shifts from the theory to its application in foreign language teaching at the same time because if teachers can combine the theory of iconicity with it, the process of learning would not be boring at all. As the paper has shown, iconicity is definitely a significant characteristic of language. It can be seen that iconicity works on all levels of language and performs a crucial role in grammar teaching, vocabulary teaching, translation teaching, as well as phonetic teaching (Hu, 2001). It is meaningful to apply the principle of iconicity to language teaching, which would bring great improvement in teaching and learning.

\subsection{Limitations}

This paper makes up for the deficiency of only theoretical studies of iconicity and possesses new value in its application of the principle of iconicity by discussing its application to English teaching. The author believes that the application of iconicity to language teaching is useful for teachers to improve the learners' language ability by clearly explaining a great variety of linguistic phenomena. The study of iconicity, however, is complicated and endless. The author merely focuses on the major part concerning this linguistic phenomenon for lack of references and application of theory into practice. Though the study of iconicity is based on reliable and valid materials, it is mostly a theoretical study which needs to be proved by teachers in their classes. Without doubt, some drawbacks exist in this research, which need further studies. For example, it is extremely incomplete to apply the principle of iconicity to only language teaching. This paper just does a tentative research, which needs to be analyzed and polished. The study of iconicity should be better and more complete if it can be applied into the field of advertising, film, Internet, music, transportation and so on. And the significant role iconicity plays in language teaching would be more persuasive if more iconic evidences are offered.

\subsection{Suggestions for Future Research}

There is still a long way to go in making the research on iconicity more complete and meaningful. When iconicity is employed to language instruction, teachers may face some obstacles, such as, how to apply the theory effectively and how to enable students to grasp it. In addition, this principle should also be applied to other areas to be more practical instead of only to language teaching. Thus, the study should be carried out more widely in the future. The author hopes that a lot of efforts would be made to get a better understanding of iconicity, which would reward not only the researchers but also students and teachers a bright future.

\section{References}

Cai, J. G. (2012). The Constraints on and Necessity for Upgrading College English Vocabulary Requirement. Journal of PLA University of Foreign Languages, 1, 48-53.

Chen, C. Y. (1995). A Little Relaxation in the Eden of Poetry---American Volume. World Book Inc.

De Saussure, F. (2011). Course in general linguistics. Columbia University Press.

Du, W. L. (1996). Iconicity in English Language. Journal of Sichuan International Studies University, 1, 60-65. 
Dai, L. H. (2004). Iconicity in Lexicon and English Vocabulary Teaching. Journal of Huaihua University, 6, 121-123.

Dong, X. L. (2010). On application of the principles of syntax iconicity in English grammar teaching. Journal of Heibei Polytechnic University (Social Science Edition), 10(5), 140-142.

Fan, L. J. (2013). Iconicity and its application to the teaching of English. (Master's thesis, China University of Petroleum, Shandong, China). Retrieved from https://www.cnki.net/

Fu, Y. L., \& Chen, P. (2003). Order Feature of Languages and Its Cognitive Experiences Based on English Su-P order. Foreign Languages and Their Teaching, 11, 6-10.

Feng, Q. H. (2002). A Practical Course Book in Translation. Shanghai Foreign Language Education Press.

Givón, T. (1995). Isomorphism in the grammatical code. Iconicity in Language, 47-76. https://doi.org/10.1075/cilt.110.07giv

Haiman, J. (1980). The Iconicity of Grammar: Isomorphism and Motivation. Language, 56(3), 515-540. https://doi.org/10.2307/414448

Han, J. Q., \& Liu, A. Y. (2000). Compatibility between Generative Grammar and Syntactic Iconicity. Journal of Foreign Languages, 3, 18-24.

Hao, S. (2006). The theory of iconicity and its application to English teaching. (Master's thesis, Jilin University, Changchun, China). Retrieved from https://www.cnki.net/

Hiraga, M. K. (1994). Diagrams and Metaphors: Iconic Aspects in Language. Journal of pragmatics, 22(1), 5-21. https://doi.org/10.1016/0378-2166(94)90053-1

Hu, Z. L. (1996). The Research Status of American Functional Linguist Givon. Contemporary Linguistics, 4, $1-10$.

Hu, Z. L. (2001). Linguistics: A Course Book. Peking University Press.

Jacobson, R. (1960). Closing Statement: Linguistics and Poetics, TA Sebeok (ed.), Style in Language.

Lakoff, G., \& Johnson, M. (1980). Metaphors We Live By. Chicago, IL: University of Chicago.

Landsberg, M. E. (Ed.). (2011). Syntactic Iconicity and Linguistic Freezes: the Human Dimension (Vol. 9). Walter de Gruyter.

Li, J. (2008). Iconicity and its application to English teaching. (Master's thesis, China University of Petroleum, Shandong, China). Retrieved from https://www.cnki.net/

Li, Y. X. (2001). Introduction to Text Translation. China Translation \& Publishing Corporation.

Lin, Y. X. (2001). Syntagmatic and Paradigmatic Relations in Linguistic Context and Translation Studies. Foreign Language Education, 2, 32-35.

Liu, S.Y. \& Cao, H. (2006). A Contrastive study of Word Order Iconicity in Chinese and English. Foreign Language Education, 6, 25-30.

Lu, W. Z. (1998). A Meticulous Research into the Figure Regression of Chinese and English. Hunan People's Publishing House. .

Lu, W. Z. (2002). The Cognitive Basis of Word Order. Journal of PLA University of Foreign Languages, 5, 5-9.

Lu, W. Z. (2003). Iconicity and Translation: Spiritual and Formal Resemblance. Journal of Foreign Languages, 6 , 62-69. https://doi.org/10.1075/z.119.11bib

Nida, E. A. (1993). Language, Culture, and Translating. Shanghai Foreign Language Education Press.

Peirce, C. S. (1940). The Philosophy of Peirce: Selected Writings. London: Routledge \& Kegan Paul.

Shen, J. X. (1993). A Survey of Studies of Iconicity in Syntax. Foreign Language Teaching and Research,1,12-17.

Wen, X. (2000). Distance Iconicity of Linguistic Symbols. Foreign Language Research, 2, 71-74.

Wang, Y. (1998). Marked Iconicity. Foreign Language Research, 3, 50-56.

Wang, Y. (1999). The Translation and Definition of Iconicity. Chinese Translators Journal, 2, 18-20.

Wang, Y. (1999). On Iconicity of Linguistic Symbols. Foreign Languages and Their Teaching, 5, 4-7.

Wang, Y. (2000). Research History of Iconicity of Linguistic Symbols. Shandong Foreign Language Teaching, 2, 
$12-35$.

Wang, Y. (2001). Semantic theory and language teaching. Shanghai Foreign Language Education Press.

Wang, Y. (2002). Philosophical Basis of and Dialectical Relations Between Iconicity and Arbitrariness. Journal of PLA University of Foreign Languages, 2, 1-6.

$\mathrm{Xu}$, G. Z. (1998). Is Language a System of Arbitrary signs? Foreign Language Teaching and Research, 3, 2-10.

Xu, Y. C. (1992). On Chinese Verse in English Rhyme. Peking University Press.

Zhao, Y. F. (2001). Introduction to Cognitive Linguistics. Shanghai Foreign Language Education Press.

Zhang, M. (1998). Cognitive Linguistics and Chinese Noun Phrases. China Social Sciences Publishing House.

Zhang, Z. (2001). On the Research of Iconicity of Language in China. Foreign Language Research, 1, 67-74.

Zhang, Z. (2004). Different Types of Iconicity of Language. Foreign Language and Literature Studies, 4, 17-21.

Zhang, Z. B. (2005). A New English Grammar Course Book. Shanghai Foreign Language Education Press.

\section{Copyrights}

Copyright for this article is retained by the author(s), with first publication rights granted to the journal.

This is an open-access article distributed under the terms and conditions of the Creative Commons Attribution license (http://creativecommons.org/licenses/by/4.0/). 